\title{
Johann Jakob Wepfer und seine Einstellung zum Aderlasse
}

\author{
Ein Briefentwurf an Georg Frank von Frankenau \\ Von P. Eichenberger, St. Gallen
}

Bei der Durchsicht von Johann JaKob Wepfers ${ }^{1}$ posthumem Werk über die Kopfkrankheiten ${ }^{2}$ fiel in bezug auf den Aderlaß immer wieder die Wendung «nisi in plethoricis» (außer bei Vollblütigen) auf. Ebenso auffällig war Wepfers Vorliebe für eine geringe Menge des abgelassenen Blutes. Eine Zusammenstellung aller Stellen aus diesem Buche über den Zeitpunkt, die Menge und die Entnahmestellen des Aderlasses, brachten außer der Bestätigung von Wepfers Zurückhaltung in bezug auf Häufigkeit des Aderlasses und geringe Blutmenge nichts Neues. Eine Ausnahme bildet vielleicht folgende Stelle: «Mit dem Aderlaß wird immer etwas Serum entzogen, der Blutandrang gemildert und das allzu heftige Sprudeln und Brausen gedämpft. Aber bisher riet ich, daß man ihn nicht zu häufig mache, da bei jedem Aderlaß eine nicht unerhebliche Menge der Geister vergeudet wird. Wegen dieser Verarmung an Geistern wird das Blut leichtflüssiger und so schließlich der Weg zum Kräftezerfall und gemäß Avicenna zur Apoplexie vorbereitet. ${ }^{3}$

Wesentlich Neues brachte der nachfolgende Briefentwurf Wepfers an Georg Frank von Frankenau (1643-1704). Frank hatte zusammen mit Wepfers Schwiegersohn, Johand Conrad Brunner (1653-1727), in Heidelberg eine Professur für Medizin innegehabt, war 1689 bei der Belagerung und Zerstörung Heidelbergs nach Wittenberg geflohen und bekleidete dort an der Universität das Amt eines Professor Publicus für Pathologie ${ }^{4}$. Diesen

${ }^{1}$ H. Fischer, Johann Jakob Wepfer (1620-1695). Ein Beitrag zur Medizingeschichte des 17. Jahrhunderts, Zürich 1931. - H. Fischer, Briefe Johann Jakob Wepfers (1620-1695) an seinen Sohn Johann Conrad (1657-1711), Studiosus Medicinae zu Basel und Leyden, Aarau 1943. - H. Nigst, Das anatomische Werk Johann Jakob Wepfers (1620-1695), Aarau 1943. - P. Eichenberger, Johann Jakob Wepfer (1620-1695) als klinischer Praktiker, Med. Diss. Basel, im Druck.

2 J. J.WEPFER, Observationes medico-practicae de affectibus capitis internis et externis, Schaffhausen 1727.

3 J. J. WePfer, Observationes ... de affectibus ... Schaffhausen 1727, S. 445.

${ }^{4}$ Georg Frank von Frankenau (3. Mai 1643 bis 16. Juni 1704) studierte zu Jena und Straßburg Medizin. 1672 wurde er Professor für Medizin an der Universität Heidelberg wie der Schwiegersohn J. J. Wepfers: Johann Conrad Brunner - und war Leibarzt des Markgrafen von Baden-Durlach und der Herzöge von Württemberg wie J. J. Wepfer, dazu noch Hausarzt des Erzbischofs von Trier. Wegen des Pfälzischen Krieges flüchtete 
Briefentwurf hatte ich im Dezember 1962 im handschriftlichen Nachlasse Wepfers in der Universitätsbibliothek Leiden gefunden ${ }^{5}$. In diesem Schreiben, datiert vom Dezember 1690, berichtet Wepfer auf Fragen Franks von seinen Erfahrungen mit dem Aderlaß in der Praxis.

Um jedoch Wepfers Maßhalten im Aderlaß zu verstehen, müssen wir zum voraus folgendes beachten.

Heinrich Screta (1637-1689) hatte autodidaktisch orientalische Sprachen studiert ${ }^{6}$ und wahrscheinlich auch verschiedene Stellen aus den Werken Avicennas für Wepfer aus dem Arabischen übersetzt. Wepfers Indikationen des Venenschnittes decken sich denn auch weitgehend mit denjenigen Avicennas, deren Bereich folgendes umfaßt: die Entleerung der überschüssigen Materie, wenn sie in Blut oder melancholischen Säften besteht. Krankheiten, die mit dieser Materie im Zusammenhang stehen, können nicht anders geheilt werden, und auch zur Vorbeugung ist der Aderlaß mit gewissen Einschränkungen geeignet. Die zweite Aufgabe des Venenschnittes ist das Herausführen der gekochten Krankheitsmaterie. Avicenna glaubt, durch den Aderlaß verdorbenes Blut direkt ausführen zu können, während das gesunde im Körper verbleibe. Also hat es einen Sinn, einen Aderlaß zu wagen bei Vollblütigkeit, Säfteverderbnis, zur Verhütung von Krankheiten; darunter fällt auch die Hämoptoe, die Organschwäche eines hitzigen Temperamentes und die Verhütung von nachfolgenden Entzündungen bei Traumen. Die Gegenindikationen waren: kaltes Temperament, kalte Gegend, heftige Schmerzanfälle nach einem Bade, Kinder unter vierzehn Jahren, Greise, blutarme und fettleibige Personen sowie Rekonvaleszenten ${ }^{7}$.

Im weiteren mag Wepfers Einstellung zum Aderlaß der Rat des Anatomen und Chirurgen Pietro Marchetti (1593-1673) beeinflußt haben, er solle sich der Gewohnheit des Aderlasses nicht zu sehr widersetzen, sonst werde er schon gleich zu Beginn der Praxis die Achtung der Leute verlieren (siehe unten S. 111). Falsche, aber weitverbreitete und festverwurzelte An-

er zuerst nach Frankfurt am Main und dann nach Wittenberg (vgl. dazu: C. BrunNer und W. von Muralt, Aus den Briefen hervorragender Schweizer Ärzte des 17. Jahrhunderts, Basel 1919, S. 401, Brief Fabricius' an J. C. Brunner, datiert Oktober 1689). Dort wurde er an der Universität ordentlicher Professor für Pathologie. Daneben war er Leibarzt des Kurfürsten Johann Georg III von Sachsen. Briefe an J. J. Wepfer befinden sich in der Zentralbibliothek Zürich (Ms Z VII 295) und in der Universitätsbibliothek Leiden ( L U B, B PL 249, litterae A-Z), haben aber keinen Zusammenhang mit dem vorliegenden Thema.

${ }^{5}$ Leiden Universitätsbibliothek (L U B ), B PL 249, fasc. 3, fol. 27 R-34 V.

6 J. J. WePFER, Observationes ... de affectibus capitis ..., Schaff hausen 1727, S. 658.

7 J. Bauer, Geschichte der Aderlässe, Neudruck München 1966. 
sichten gab es auch damals schon im Volke. Wepfer nennt denn auch den Aderlaß ein Allerwelts- und Abwehrmittel gegen alle möglichen Krankheiten, dem die Leute gerne die Schuld in die Schuhe schieben, wenn sich ein erwarteter Therapieerfolg nicht einstellt. Aber auch die Ansicht, der Aderlaß verhelfe zu einer glücklichen Geburt und zu einem beschwerdefreien Wochenbett, machten Wepfer zu schaffen (siehe unten S. 111 und S. 130).

Ein anderer Punkt, der beachtet werden muß, ist Wepfers volles Bekenntnis zum Blutkreislauf und damit die Beschränkung der Gesamtblutmenge auf ungefähr 6-7 Liter. Als Wepfer in den Jahren 1639-1643 beim Anatomen Melchior Sebiz II (1578-1674) in Straßburg studierte, wurde er auf zwei veröffentlichte Briefe von JAN DE WALE (1604-1649) über den Fluß der Lymphe und des Blutes aufmerksam. Nach dem Wechsel an die Universität Basel wagte er sich noch nicht darüber zu äußern, und erst nach seinem Paduaner Studienaufenthalt bekennt sich Wepfer voll zum Anhänger von Harveys Blutkreislauf ${ }^{8}$.

Nicht unwesentlich scheint mir auch folgendes Erlebnis Wepfers gewesen zu sein: Er ließ sich zwischen dem 17. und 24. Altersjahr wegen Zahnschmerzen zur Ader und fiel zweimal in Ohnmacht, obwohl nur wenig Blut herausgelassen wurde (siehe unten S. 128). Solche persönlichen Erlebnisse pflegen einen viel größeren Einfluß auf eine grundsätzliche Einstellung zu nehmen, als man gemeinhin annimmt.

Ein Problem war auch schon damals das kommerzielle Denken der Patienten. Ein Ratsherr hatte sich vom Bader zur Krankheitsprophylaxe einen Aderlaß machen lassen. Der Bader zapfte ungefähr $700 \mathrm{ml}$ ab, und dies bekam dem Patienten schlecht. Als Wepfer den Bader zur Rede stellte, antwortete dieser, er mache es ja nur, damit die Leute nicht behaupten könnten, er lasse sich für einen kleinen Eingriff gut bezahlen. Wepfers Aderlaßmenge betrug im Durchschnitt $80-150 \mathrm{ml}$, im Maximum und selten $200 \mathrm{ml}$ (siehe unten S. 114).

Im folgenden soll nun Wepfers Briefentwurf in deutscher Übersetzung wiedergegeben werden. Das handschriftliche, lateinische Original umfaßt acht Quartseiten, zeigt Streichungen, Wiederholungen und manchmal auch kaum lesbare Stellen. Man spürt die Welt des Barocks, aus der Wepfer zu uns spricht, und ist vielleicht gerade deswegen über die kühle Sachlichkeit unseres großen Schweizer Arztes erstaunt.

8 P. Eichenderger, Autobiographisches von Johann Jakob Wepfer (1620-1695) in einem Briefwechsel mit Johann Conrad Brotbeck (1620-1677), Gesnerus 24 (1967) 13. 
«Herr Doktor Frank, öffentlicher Professor für Pathologie in Wittenberg, Sächsischer Stadtarzt, möchte wissen, ob ich Kindern und gänzlich Gesunden zum Aderlaß rate, wieviel und mit welchem Erfolg; ob ich eine beachtliche Menge, d.h. bis zu Pfunden, ohne Schaden und mit welcher Art von Aderlaß herauslasse, mit welchem sofortigen oder späteren Schaden; ob ich den Aderlaß mehrmals am gleichen Tage oder bei der gleichen Krankheit wiederholt wage und mit welchem Erfolg; ob ich beim Aderlaß einen beachtlichen Nutzen oder Nachteil beobachtet habe bei verschiedenen oder der gleichen Krankheit; welche Art von Blut ich beim Aderlaß beobachtet hätte, ob Chylus, Eiter, Milch, Urin, Fasern, Körnchen oder Steinchen mit dem Blut herausgeflossen oder später daraus entstanden seien. Den Brief solle ich nach Nürnberg zu Herrn Doktor Volckamer ${ }^{9}$ senden.

Ich antwortete im Dezember 1690.

Die Aderlässe sind bei uns und in der Nachbarschaft äußerst häufig, eine Panazee (Allerweltsheilmittel) und Abwehrmittel für drohende und befürchtete Krankheiten. Meistens ordnet man sie an, um vorzubeugen, manchmal wegen eines verschleppten Leidens, dem die Patienten unterworfen sind, oder aber sie werden schon von ihm heimgesucht, müssen deswegen noch nicht im Bett liegen, gehen herum und kommen noch irgendwie ihren Pflichten nach. Wenige wenden den Aderlaß zu Beginn der Krankheit an. Viele ... [?] vernachlässigen oder verweigern ihn, sobald sie bettlägerig sind und er nützlich wäre. Und wenn sich gar später ein Erfolg nicht wunschgemäß einstellt, beschuldigen die den Aderlaß, was man durchaus andern Fehlern besonders dem Weintrinken bis zum dritten Tage bei akuten Krankheiten zuschreiben muß.

Insbesondere aber muß man den richtigen Zeitpunkt im Auge behalten. Als ich 1647 aus Italien nach Basel zurückkehrte und in Kürze eine ärztliche Praxis zu Hause in Erwägung zog, mahnte mich der berühmte Herr Doktor Marchetti ${ }^{10}$, ein bekannter Praktiker, ich solle mich dieser Gewohnheit [des Aderlasses] nicht zu sehr widersetzen, sonst würde ich schon gleich zu Beginn die Achtung der Leute verlieren. Diesen Rat habe ich getreulich befolgt, und Erfolg und Mißerfolg des Venenschnittes waren mir nie gleichgültig.

9 Johann Georg Volckamer (9. Juni 1616 bis 17. Mai 1693) studierte zu Jena und Altdorf Medizin, ebenso drei Jahre in Padua. Er promovierte 1642 in Altdorf und wurde 1683 Präsident der Kaiserlichen Leopoldinisch-Karolinischen Akademie.

10 Pietro Marchetti (1593-1673) war Professor für Anatomie und Chirurgie in Padua, Lehrer J. J. WePfens in seiner Paduaner Studienzeit (1644-1646). 
Als ordentlicher Arzt des Klosters der Benediktinerpatres in Rheinau ${ }^{11}$, in unserer Nachbarschaft, mache ich ihn schon seit 40 Jahren, in St. Blasien im Schwarzwald seit 26 Jahren. Zweimal im Jahre, an bestimmten Tagen, im Frühjahr und Herbst, komme ich dort an. Später befrage ich in Anwesenheit von Hochwürden Prior jeden Pater nach seiner Gesundheit. Je nachdem wie ein Leiden bei irgend einem sich zeigt, verschreibe ich Medikamente. Am festgelegten Aderlaßtage besuche ich sie wieder.

Eine vorher bestimmte Ader wird jenen, denen ein Aderlaß verordnet wurde, in meiner Anwesenheit durchstoßen und soviel als ich befehle herausgelassen. Dieses Blut wird an einen vorbereiteten und dunklen Ort gebracht und nach einigen Stunden einzeln betrachtet und untersucht. Sorgsam wird darauf geachtet, wie jeder Pater fernerhin seine Gesundheit pflegen müsse. Die Beobachtungen schreibe ich fortlaufend in ein Buch ein, wovon ich schon mehrere Bände besitze ${ }^{12}$. Sollte zufällig einer von ihnen eine Änderung von seiten seiner Gesundheit erfahren, hat dies den Vorteil, daß wir, mein Sohn ${ }^{13}$ oder ich, sofort wissen, wie der Kranke rasch, wirksam und mit Erfolg zu behandeln ist.

[Randbemerkung:] Das machte schon Herr Doktor Johann Burgauer ${ }^{14}$, mein Vorgänger; ebenso Fabricius Hildanus ${ }^{15}$... [?], Rhodius in Padua ${ }^{16}$... [?]. Diesen löblichen und sehr

11 J. J. Wepfer wurde Nachfolger dieses Amtes nach dem Tode von Johann Screta (gestorben 7. Januar 1650). Vgl. P. Eichenberger, J. J. Wepfer als klinischer Praktiker, Med. Diss. Basel, im Druck.

12 In WePFers Nachlaß in der Universität Leiden finden wir diese Bücher: Das eine, die Examina St. Blasii (LU B, B PL 249, fasc. 13), wie das andere, die Examina Rheinoviana (LU B, BPL 249, fasc. 14) enthalten Einträge von 1681-1694 bzw. 1666-1693 und sind 170 bzw. 199 folia stark.

13 Johann Conrad Wepfer (7. Juli 1657 bis 16. Juni 1711). Vgl. H. Fischer, Briefe J. J. Wepfers an seinen Sohn, Studiosus zu Basel und Leiden, Aarau 1943.

14 Johann II Burgauer (21. September 1600 bis 28. Mai 1635) wurde 1627 Stadtarzt von Schaffhausen und starb an der Pest. Bis zu seinem Tode hatte er noch den 15 jährigen WEPFER betreut, der damals auch an der Pest, allerdings nur leicht erkrankt war. Wepfer muß Burgauers Krankengeschichten oder Praxisbücher besessen haben, denn in der 2. Ausgabe der Observationes anatomicae ex cadaveribus eorum, quos sustulit apoplexia von 1675 werden einige dieser Krankheitsberichte verwertet.

15 Wilhelm Fabry von Hilden, genannt Fabricius Hildanus (25. Juni 1560 bis 15. Februar 1634), war Chirurg und von 1615-1634 Stadtarzt von Bern.

16 Johannes Rhode (gegen 1587 bis 24 . Februar 1659) war Arzt in Padua und schrieb eine Introductio ad Medicinam paulo accuratiorem et Bibliotheca medica. Diese wurde in HERMANN ConRINgs Introductio in universam artem medicam singulasque eius partes, 1687 in Helmstedt, von GüNther Christoph Schelhammer herausgegeben, und zwar zum ersten Male, direkt aus dem Manuskript. In Schelhammers Ausgabe sind fünf Beiträge 
nützlichen Grundsatz lernte ich in Rom im Spital S. H., das ich oft zusammen mit dem später berühmten Petrus Servius ${ }^{17}$ besuchte, auch vom bekannten Rhodius, in dessen Gemeinschaft ich über zwei Jahre lebte [vgl. ${ }^{16}$ ], nachdem ich ihm empfohlen worden war. Im Hypogäum [Spital] sind die Kranken in Gruppen eingeteilt. Es waren im ganzen vier: Jede umfaßte 25 Betten, alle mit Nummern versehen. An jedem hingen drei schwarze Tafeln. Herr Servius besuchte jeden Morgen die ihn erwartenden Patienten zusammen mit einem jüngeren Arzt und den Gehilfen des Apothekers, des Chirurgen und des Kochs. Nachdem er jeden Kranken der Reihe nach untersucht hatte, diktierte er, was der Apotheker, was der Chirurg und was der Koch zu tun hätten. Dies wurde auf die einzelnen Tafeln geschrieben und alle zusammen in einen Korb geworfen. Der junge Arzt schrieb alles in ein Buch ein. Er beobachtete auch die Erfolge und trug sie ein ... [?].

Die gleiche Methode gebrauche ich auch bei andern, die ständig meiner Hilfe bedürfen, besonders bei den Vornehmen, am Hofe bei den Prinzen und Grafen, in deren Lohn ich stehe ${ }^{18}$. (Was mir von diesen Beobachtungen aber geeignet erscheint, um damit Deine Fragen kurz gefaßt zu beantworten, teile ich Dir einfach kommentarlos mit, was Du gutheißen magst.) Nun komme ich zu den Fragen.

von Ärzten der damaligen Zeit zusammengefaßt, und zwar Hermann Conring, Caspar Bartholin (Großvater), Pietro Castelli, Johannes van der Linden und Johann RHODE.

Johann Rhode gibt in dieser Einführung knapp zusammengefaßt den Lehrgang eines idealen Medizinstudiums von sechs Jahren an, indem er die zu lesenden und zu bearbeitenden Werke anführt. Unter Annus V, S. 132, Zeile 21-27, finden sich einige Sätze über das Schreiben von Krankengeschichten, wie sie WEPFER erwähnt hat: «Naturae et effectus et eventus rariores inter ipsas operas notentur, imo suo quique ordine aegri, quotquot occurunt, diligenter in historiam reponendi, praemissis naturalibus et non naturalibus, antequam praeternaturalia enumerentur, annotatis omnibus exquisite remediis. Quae vero longis experimentis fidem promeruerit, tum simplicia, tum composita, suis quaeque titulis subsignentur, ut poscente usu prompta sint.»

Auch aus einem undatierten Brief Wepfers an Johann Heinrich Boecler (1611-1672), Professor der Beredsamkeit in Straßburg, den mir freundlicherweise die Staats- und Universitätsbibliothek Hamburg (Sup. ep. 311) als Mikrofoto überließ, geht hervor, daß J. J. Wepfer bei Johann Rhode im Hause «al pozo depinto alla porta verde» gelebt hatte.

17 Pietro Servi (gestorben 1648) war Professor der Medizin in Rom und in vielem ein Anhänger Galens. Dies ersieht man aus der Wertung, die G. C. Schelhammer in den Bemerkungen zu Hermann Conrings Introductio (siehe Anm. 16) gibt: «Vixit ibidem (= Rom) eodem tempore Petrus Servius itidem doctissimus, qui varia quoque scripsit. Galenicae doctrinae nimium in quibusdam videtur adhaesisse, quamvis in aliis ab ea recedat, ut in libro de Unguento Armario.» Vgl. P. Eichenberger, Autobiographisches von J. J.Wepfer in einem Briefwechsel mit J. C. Brotbeck, Gesnerus 24 (1967) 14, Anm. 34.

${ }^{18}$ Er wurde 1675 Leibarzt des Markgrafen von Baden-Durlach und zugleich der Herzöge von Württemberg. 
$\mathrm{zu} 1$

Bei den 12- bis 13 jährigen Knaben, die schon zwei-, dreimal eine Brustfellentzündung hatten, sorgte ich für einen Aderlaß, bei jüngeren, auch wenn sie kräftig [?] sind, dagegen niemals. Noch viel weniger bei Kleinkindern und zwar nicht, weil sie den Aderlaß nicht ertrügen; denn täglich beobachten wir Knaben und Mädchen, die ohne Schaden bis zu einigen Unzen ${ }^{19}$ Blut verlieren, entweder durch Nasenbluten, Wunden von Stößen und Schlägen oder sonstigen Haut- oder Fleischwunden. Mehrere Greise von sechzig, sogar siebzig Jahren, auch im Kloster, lassen sich wie gewohnt zur Ader. Unterlassen sie es, so geht es ihnen, wie sie glauben, im ganzen Halbjahr schlechter, und manchmal ist es wirklich so, denn sie klagen über Abgeschlagenheit, Schwere im Kopf und Schwindel. Sie glauben, so könnten sie die Katarrhe und den Hirnschlag vermeiden, was aber nicht immer zutrifft.

In meinen Notizen fand ich einen, der sonst vollblütig, am Tage nach dem Aderlaß an einem heftigen Hirnschlag verstarb. Man glaubt aber, daß er einen andern Fehler begangen habe. Hochwürden Abt Bernhard selig ließ sich bis zum 80. Altersjahr zweimal jährlich zur Ader und ertrug es gut. Und ein anderer würdiger Greis und unvergleichlich gelehrter Mann, eifrig Bücher schreibend, mit einem guten Gedächtnis und ebensolcher Urteilskraft, drängte, im gleichen Alter stehend, im vergangenen Herbst auf einen Aderlaß. Er wurde ihm nicht verweigert, war allerdings spärlich und ohne Schaden für ihn. Ebenso wurde eine Nonne, die bis zum 84. Lebensjahr zweimal mit dem Aderlaß fortfuhr, 88jährig.

\section{zu 2}

Wenn ich beim Aderlaß anwesend war, habe ich meistens drei bis fünf Unzen $^{19}$ Blut herausgelassen, selten über ein halbes Pfund ${ }^{20}$. Größere Mengen zu lassen, ging bei mehreren übel aus, wie ich beobachtet habe. Es ist dies auch keinem Ausgezehrten (cachecticus) bekömmlich. Ein gewisser Ratsherr, ein sonst stämmiger Mann, verlangte vom Bader - es war dies im Anfang meiner Praxis -, ihm die Vene zu öffnen, allerdings ohne vorher eine Diät zu versuchen. Dieser ließ zwei Pfund heraus, und der Patient wurde kachektisch und begann mühsam zu atmen. Bald darauf befiel ihn die Wassersucht, und vom Mißbrauch von Abführmitteln eines Pfuschers starb er kurz hernach. Als ich den Bader im Beisein des Kranken anfuhr, soviel Blut herausgelassen zu haben, antwortete dieser, er mache es deshalb, damit ihm

19 uncia, Unze $=28,8 \mathrm{~g}$ nach heutigem englischem Maß.

20 libra, Pfund $=12$ Unzen $=345,6 \mathrm{~g}$ nach heutigem englischem Maß. 
niemand vorwerfe, er nehme einen großen Lohn, wenn wenig Blut herausfließe. Es sind wenige Jahre her, als ein vornehmer Herr bei einem Sturz mit dem Hinterkopf stark aufschlug und nach wenigen Stunden apoplektisch wurde. Von andern berühmten Ärzten, wie auch von mir, wurde zur Rasur der Haare geraten. Wir konnten keine Prellung feststellen. Da der Kranke schon vor dem Sturz seit mehreren Wochen alles Essen erbrochen hatte und schon ganz mager und schwach war, wagten wir den Aderlaß nicht. Wir rieten zu größeren Schröpfköpfen, die man nach Hautritzung (sacrificatio) mit großer Flamme aufsetzen solle, zu blasenziehenden Pflastern und zu scharfen Einläufen. Ein französischer Arzt von vorzüglichem Rufe wurde nach einigen Stunden vom Fürsten zu Hilfe geschickt. Bei der Ankunft ließ er sich mit einer gewissen selbstgefälligen Würde darüber aus, daß es eine schwere Krankheit sei, die die Anwendung eines gewichtigen Mittels fordere, wie das eben der Aderlaß sei. Seine Ansicht begründete er mit Stellen aus Galen. Diesem jedoch hielten wir entgegen, daß der Kranke Mühe habe, die Blutvorräte, wegen des täglichen Erbrechens aller Speisen, zu erneuern, und daß durch ein weiteres Vergießen der Lebensfaden bald abgerissen oder sogar jäh abgeschnitten werde. Aber nachdem er unsere Argumente zurückgewiesen hatte, befahl er einen Aderlaß, um seine große Autorität zu beweisen. Vielleicht wollte er unsere Worte nicht hören und befahl daher erst dann die Ader zu schließen, als drei und mehr Pfund ${ }^{20}$ herausgeflossen waren, d.h. nachdem er gefühlt hatte, daß sich der Puls auf der Gegenseite zu verringern begann ... [?]

Kurz darauf bekam er am stärksten auf der Gegenseite [des Aderlasses] einen Krampfanfall und hörte nach wenigen Stunden zu leben auf. Der größte Teil des herausgelassenen Blutes war Serum, in dem Gerinnsel schwammen. Nachdem der Schädel abgedeckt war, fand ich den Raum zwischen den Hirnhäuten und auch den Ventrikel voll ähnlichen Serums. Ich fand jedoch keinen Bruch oder Spalt der Kalotte, aber an der Basis, in der Nähe des Türkensattels, einen breiten Spalt zwischen Felsenbein und Keilbein, wo ohne Zweifel ein Arterienast gerissen war. Mehr als einmal habe ich nicht ohne Verwunderung beobachtet, daß nicht selten mehrere Pfund Blut aus Nase, Magen, Hämorrhoiden, Uterus oder Nieren ohne Schaden verloren werden konnten. Einige entgingen der Auszehrung (cachexia) und starben, mehrere erlangten jedoch in Kürze vom gewohnten Essen die alten Kräfte. Es gibt bei uns eine Familie, in der schon die meisten ein schweres Nasenbluten erlebt hatten. Einer von ihnen kam auch in höheres Alter und führte den Ratsvorsitz während einiger Jahre ausgezeichnet. Ein anderer, 
nach einer Blutung schon bewußtlos, erholte sich davon. Er befahl jeweils, war es nun Frühling, Sommer oder Herbst, den Ofen stark zu heizen, setzte sich dahinter, bedeckte das Haupt mit einer Pelzkappe und trank ausgiebig roten Schaffhauser Wein, d.h. er leerte einen Becher von über drei Pfund ${ }^{20}$. So stellte er allmählich seine Kräfte wieder her und erlangte die gewohnte Frische. Monsieur Lachar, ein verbannter Franzose, 62 jährig, von Montpellier, machte im vergangenen Frühjahr ein epidemisches, bösartiges Fieber (Typhus?) durch und litt an Schmerzen unter dem Rippenbogen neben der Linea alba. Nachdem er dies überstanden hatte, schwächte ihn unter einigen Malen eine Gelbsucht. Oft mußte er gallig erbrechen. Neulich, am 10. Dezember, obwohl er sich nicht allzu schlecht zu fühlen schien, erbrach er bis 4. Pfund reines Blut mit Gerinnseln. Nachts zehn Uhr wiederum zwei Pfund. Ich empfahl Ruhe und eine adstringierende Mixtur. Als Getränk riet ich zu einer Emulsion aus süßen Mandeln ${ }^{21}$. Für die Suppe koche man zusammen mit Fleisch zwei Drachmen Hauseblasen ${ }^{22}$. Am 11. Dezember schied er auf dem Stuhl ganz schwarzen, pechartigen und stark stinkenden Kot aus, was nichts anderes als Gerinnsel sein konnte. Das bewies ich dadurch, daß nach Zuschütten von lauem Wasser, die darin eingedrückten Tücher sich blutig färbten. Mit anregenden Mitteln und Ruhe erlangte er schnell seine Kräfte wieder, und schon am anderen Tage, nach dem Bluterbrechen, tastete ich einen gefüllten Puls. Während ich dies schreibe, fühlt er sich ganz gut.

Vor dreißig Jahren erbrach Pater Jannuarius Renner von Rheinau ${ }^{23}$ in einer Woche mehrere Pfund Blut. Er war schon ganz schwach, als ich zu ihm gerufen wurde. Er wurde blaß wie ein Leintuch und steif wie ein Brett, als man ihn von seinem Bett in ein anderes brachte. Wenn er die Hand zum Munde führte, wurde er sofort bewußtlos. Außer mit blutstillenden Mitteln

21 Süße Mandeln enthalten nach den Documenta Geigy, Wissenschaftliche Tabellen, in $100 \mathrm{~g}$ eßbarer Substanz: 4,7 g Wasser, 18,6 g Protein, 54,1 g Total Fett, 10,8 g Polyenfettsäuren, 19,6 g Kohlehydrate, 2,7 g Faserstoffe neben Vitaminen und Spurenelementen. Nach KleEberg, Mandeln als Heilnahrung in der Inneren Medizin, Therapeutische Umschau 22 (1965) 458-464, setzt das Mandelöl im Duodenum das Enterogastron frei. Dieses setzt die Motilität und Sekretion im Magen auf humoralem Wege herab und bewirkt so, neben der Funktion als Schutzfilm im Magen selbst, eine Besserung der Beschwerden.

22 Ichthyocolla = Hauseblasęn. Hauseblasen sind die Schwimmblasen von Acipenser Huso L., ein Fisch aus der Abteilung der Ganoiden. Die Hauptmasse der Hauseblasen ist tierischer Leim (Kollagen).

23 Von Pater Jannuarius Renner von Rheinau findet sich ein Brief an Wepfer in der Universitätsbibliothek Leiden ( L U B, B PL 249, litterae A-Z). Er nimmt jedoch nicht Bezug auf das hier angegebene Herzwasser. Auch in der Pharmakopö Schroeder konnte darüber nichts gefunden werden. 
machte er eine Kur mit einer Emulsion aus süßen Mandeln mit nichtgesalzener Hühnerbrühe, die er aus dem Becher mit einem Röhrlein trank. Als er sich wieder erholt hatte, gab ich ihm eine Brühe, die viel Gelatine aus Kalb- und Hühnerfleisch und aus Kalbsbeinen enthielt. Als er schließlich eingeweichtes Brot schlucken wollte, erlaubte ich es ihm, zuerst mit wenig Wein, der mit einem Absud aus Blutwurz ${ }^{24}$ vedünnt war, schließlich auch mehr und unverdünnt. Davon wurde er erstaunlicherweise gesund. Diesen Wein nannte man später das berühmte Herzwasser des Pater Jannuarius. Er lebte noch zehn Jahre und starb dann an einer Wassersucht. Ich habe in meinen Notizen geschrieben, auf diese Weise seien auch noch andere davongekommen. Ein anderes Schicksal war einem Kapuziner in Engen, in unserer Nachbarschaft, beschieden. Als ich den berühmten Herrn Maximilian, den Grafen von Fürstenberg, behandelte, der an einer schweren Krankheit darniederlag, wurde ich ungefähr morgens acht Uhr zu jenem gerufen. Als ich kam, fand ich ihn im Refektorium bald stehend, bald sitzend ... [?], noch nicht allzu schwach und sah, daß die Kapuze schon voll Blutgerinnsel war. Ich befahl ihn ins Bett zu legen. Dann eilte ich aus dem Kloster ins Schloß, um das Nötigste, das diese Bedürfnislosen nicht besaßen, vorzubereiten. Ich hatte kaum das Schloß erreicht, als ich das Glockenzeichen für den bereits gestorbenen Todkranken hörte. Ich habe verheiratete, verwitwete und ledige Frauen gekannt, die die bekannte Blutfülle gewohnheitsmäßig und auch noch kurz vor der Zeit, da die Menstruation aufzuhören pflegt, mit dem Aderlaß herausließen. Einige von diesen sind bis zum heutigen Tage gesund. Ein anderes Schicksal droht den Schwangeren, besonders vor und nach der Geburt, meistens bei Retention des Mutterkuchens. Entweder stirbt das Kind allein oder dann zusammen mit der Mutter. Mit großer Mühe habe ich, Gott sei es gedankt, einige wiederhergestellt und gleichzeitig das Kind ... [?] gerettet. Bei einigen blúten die Hämorrhoiden sehr reichlich und lange. Dennoch muß man ihnen helfen, und sie werden meistens ohne Hydrops gesund.

Mehrere brauchten meine Hilfe; sie lösten lange Zeit und bei der geringsten Körperbewegung blutigen Urin, einer über zwei Jahre, ein anderer über

24 Radix Tormentillae. NACH HAGER, Handbuch der pharmaceutischen Praxis, Berlin 1905, Band 2, S. 1053: «Bestandtheile. Gerbstoff (Tormentillgerbsäure) bis 20 Proc., Tormentillroth (aus dem Gerbstoff entstandenes Phlobaphen), Chinovasäure, Ellagsäure, Asche 3,18 Proc. Anwendung. Wurde wegen ihres hohen Gerbstoffgehalts früher vielfach als «deutsche Ratanhia » bei ruhrartigen Erkrankungen in der Abkochung $(5,0-20,0: 100,0)$ angewendet. 
ein Jahr. Als sie schließlich einige rauhe Steinchen ausgeschieden hatten, waren sie ganz gesund und leben noch heute. Beim Blutspucken geht es mit dem Auswurf von blutigem Sputum meistens schlecht aus, sehr selten gelangen diese Kranken bis zur Auszehrung. Dennoch habe ich den einen oder anderen mit Gottes Hilfe davor bewahrt.

zu 3

Um vorzubeugen erlaube ich den Aderla $\beta$, manchmal zwei am gleichen Tage, was Fabricius irgendwo einen neronianischen Aderla $\beta^{25}$ nennt. Aber unser Volk und die Bauern lassen am gleichen Tage bis zu dreimal zur Ader. Sie glauben nicht daran, daß sie sich damit das Ende beschleunigen. Bei vielen ging es sehr übel aus. Diesen Mißbrauch habe ich in Beobachtung 3, Anatomie des Hirnschlags, S. 12, beschrieben ${ }^{26}$. Ich habe, um Brustfellententzündungen zu heilen, innert 24 Stunden zweimal zum Aderlaß geraten, zuerst auf der gesunden Seite, nach zwölf oder vierzehn Stunden auf der erkrankten Seite. Im Jahre 1647, als im Spätherbst die Dysenterie wütete, kam im Dezember und in den folgenden Monaten eine Epidemie von Brust-

25 Fabricius Filldanus, Von der Fürtrefflichkeit und Nutz der Anatomy, Herausgeber F. DE Quervain und H. Bloesch, Aarau/Leipzig 1936, S. 31-32: «Dieweil der Aderlaß alhie gedacht wird, ist dieses großen und verderblichen mißbrauchs, so bey Vielen und insonderheit alhie in dieser Statt und andern Örtern der Eidgenoßschaft (dann anderswo hab ich dergleichen nicht gesehen) ist ingerissen, auch nicht zu vergessen, namlich, daß viele vermeinent, sie wollen es gar gut machen und wol treffen, sich zwo, drey, auch wol vier Adern an underscheidlichen Örtern des Leibs öffnen und so lang bluten lassen, bis sie für tot dahinfallen. An underscheidlichen Örtern des Leibs, sage ich, als zum Exempel am rechten und lincken Arme, oder im rechten Ellenbogen und auff der lincken Handt zugleich, auch wol auff beiden Händen und Füßen zugleich, ja ich weiß, daß auch von fürnehmen Leuthen (dann der gemeine Pofel solchem Wollust selten kann abwarten) gefunden werden, welche, nachdem sie im Bad geschwitzet, geschrepfet und die Natur jetz blöd und schwach worden ist, gleichwol alsbald nach dem Bad sich an beiden Händen oder an einem Armen und Schenkel, auch wol an allen vieren zugleich, die Adern haben öffnen und ihr Blut abziehen lassen; als wann sie ihres Lebens satt weren und sich mutwilliger Weiß dessen berauben wolten. Ist fürwar ein großer Mißbrauch, auß welchem nichts anders als eine Verderbung und Verwüstung der Naturen des Menschen erfolget, und deswegen nicht Galenica, sondern vielmehr Neroniana venae sectio kann genennet werden. Dann jene befürdert und dienet zu der Gesundheit des Menschen; diese aber gereichet, wie gesagt, zu der Verderbung und Verwüstung derselben, wie auss nachfolgenden Exempeln leichtlich ist abzunehmen.»

${ }^{26}$ J. J. WEPFER, Observationes anatomicae ex cadaveribus eorum, quos sustulit apoplexia, Beobachtung 3, S. 12 (Ausgabe 1658 und 1675): Es handelt sich um eine 60jährige Bäuerin von Löhningen, Anna Walther mit Namen, Mutter mehrerer Kinder. «Häufig ließ sie Blut, sowohl mit dem Aderlaß wie auch mit Skarifikationen, nach dem üblen Brauch 
fellentzündungen hinzu. Aus diesem Grunde riet ich mehreren mit gutem Erfolg zum Aderla $\beta$ und erntete so, soeben aus Italien zurück, mit Gottes Gnade den ersten Beifall. Dieser Methode folgte ich mehrere Jahre. 1664 wurde ich zum Bürgermeister von Ewattingen im Schwarzwald gerufen. Um Mitternacht kam ich dort an und fand den sonst vollblütigen und kräftigen Mann sehr schwer atmend. Sofort bereitete ich einen Aderlaß vor und einen andern für den folgenden Tag. Bald atmete der Kranke freier und genas. Am dritten Tage stritt sich ein gebildeter Mann von bekanntem Namen mit mir, da er anders als ich von den Helmontianern überzeugt war, und fragte, warum ich zum Aderlasse geraten habe, da doch alles, richtig vorbereitet, mit Bocksblut ${ }^{27}$ besser durchgeführt werden könne. Ich antwortete,

der Unsrigen. Unsere Landsleute, die Bauern besonders, mißbrauchen den Aderlaß. Dreibis viermal im Jahr lassen sie jedesmal zwei, manchmal auch drei, nicht selten vier Venen anstechen. Oft lassen sie zwei Pfund $[=691,2 \mathrm{~g}]$ Blut heraus. Sie kümmern sich nicht um Temperament, noch um Geschlecht, noch um Alter. Manchmal sieht man Schwangere, die während der Schwangerschaft zwei bis drei Mal zur Ader lassen und sich vor dem Geburtstermin nicht mäßigen, überzeugt ein besseres Wochenbett zu haben. Ich sah Greise von achtzig Jahren, die an diese Art von Heilmittel gewöhnt waren. Nach dem Aderlaß sind sie ganz erregt, weshalb die entleerten Venen mit besserem Blut aufgefülllt werden müssen. Allzu häufig stopfen sie sofort nach dem Aderlasse ihre Körper mit Speis und Trank überreichlich voll. Öfters sieht man sie aus unserer Stadt wanken mit Füßen, die nicht mehr auf den Weg achten. Noch häufiger kehren sie schon am nächsten Tage zur angewohnten Lebensweise und zu ihrer täglichen Arbeit zurück, von andern Fehlern ganz zu schweigen.»

27 Sanguis Hirci = Bocksblut. Nach Hager, Handbuch der pharmaceutischen Praxis, Berlin 1905, Band 2, S. 815: «Das (nicht defibrinierte) eingetrocknete Blut des Rindes. Es wird im Handel bezogen und als Pulver vorräthig gehalten. In vielen Gegenden Deutschlands ist das Bocksblut noch Volksheilmittel, besonders bei Lungenentzündungen, Blutspeien, Blutflüssen, überhaupt bei allen Krankheiten, von welchen nach Ansicht des Volkes das Blut die Ursache ist.»

Johann Christian Schroeder, Artzney-Schatz, Nürnberg 1746, S. 1706 :

«Der Edle Helmont lobet auch, Tr. Pleura furens, 23, ermeldetes Bocks-Blut im Seitenstechen und Entzündungen der Lungen, nicht zwar das gemeine, daß man feil hat, sondern das folgende Weise gesammelt worden ...»

«Von diesem Blut hat Helmontius in dem Tractat. Pleura furens genannt, feine Sachen geschrieben, dem auch Zwölferus Beyfall giebet. Es ist ein berühmtes Mittel wider Pleurisin, so man desselben $\tilde{j} \mathrm{j}[=1$ Drachme $=3,6 \mathrm{~g}]$ gebrauchet. Wenn man es ordentlicher Weise sammlet, so dienet es sehr wohl das Geblüt, so von Fallen oder verheben, oder Stossen verstocket ist, aufzulösen. Nimmt man es mit Wein-Essig ein, treibet es gewaltig den Harn und ist ein treffliches Diureticum. Etliche bereiten auch einen Podagrischen Balsam draus. Den Stein zermalmet es ebenmäßig, daß ihrer viele vor ein großes Arcanum halten.» 
daß jenes von diesem Kranken bereits in großen Mengen vergeblich verschlungen worden sei, und wenn ich nicht den Aderlaß angewandt hätte, dieser wohl kaum zwei Tage überlebt hätte. Solches habe ich vorher und öfters nachher bei andauernden Fiebern mit Erfolg gewagt. Um jene Zeit ordnete ich bei einer vornehmen, schwangeren Frau am linken Arm, auf der gesunden Seite, nachts zehn Uhr einen Aderlaß mit gutem Erfolg an. Als in dieser Gegend nach dem Türkischen Kriege ${ }^{28}$ die bösartigen Fieber zunahmen, riet ich seltener und nur am ersten Tage zum Aderlasse. Der schweißtreibende Bezoar ${ }^{29}$ war bei mehreren Kranken erfolgreich.

(Hier steht dem Abschweifen über die Anwendung des Venenschnittes bei intermittierenden und konstanten Fiebern ein weites Feld offen, wenn nur Zeit und Muße es erlauben würden. Wieviel die Pariser zur Ader lassen, besonders bei Fiebern, magst Du aus den Briefen des Guy Patin, gedruckt zu ... [?], Brief 3, entnehmen ${ }^{30}$. Kein Heilmittel begünstige mehr die Wunderdinge. Einem Rheumatiker sei innert acht Monaten 64 mal zur Ader gelassen worden, d. h. es sei ein großes Wunder. Drawiz ${ }^{31}$ heilt die fliegende Gliedersucht (arthritis vaga) in kürzerer Zeit. In einem bestimmten Brief nennt Patin den Helmont ${ }^{32}$ einen ,mechant pendart Flamand“ (einen boshaften, flämischen Galgenstrick), der rasend und to-

${ }^{28}$ Der Türkische Krieg $=1683$ Belagerung von Wien durch die Türken, Entsatzschlacht am Kahlenberg.

29 Diaphoretica Bezoardica. Beide Ausdrücke sagen aus, daß es sich um schweißtreibende Mittel handelt. W. SchNeIDER, Lexikon alchemistisch-pharmazeutischer Symbole, Weinheim 1962, S. 67: «Bezoar. Kugelförmige Konkretionen aus dem Magen (Pansen) verschiedener Wiederkäuer. Bezoar orientale, vom Bezoarbock (Indien, Persien), war sehr teuer; B. occidentale, von Kamelziegen und Schafkamel (Peru), war wohlfeiler. Sollte harn- und schweißtreibend wirken und dadurch den Körper entgiften. Allgemein nannte man schweißtreibende Mittel Bezoardica. » Unter die Bezoardica gehörte auch das Antimontetroxyd $\left(\mathrm{Sb}_{2} \mathrm{O}_{4}\right)$. Daneben ist nach HAGer, Handbuch der pharmaceutischen Praxis, Berlin 1905, Band 2, S. 279-280, auch noch eine Bezoarwurzel bekannt, auch Klettenwurzel genannt (Arctium Lappa L.), die schweißtreibend wirkt.

${ }^{30}$ Guy Patin (30. August 1601/02-1672). Er war Dekan der Pariser Medizinischen Fakultät, ein großer Satiriker und gegen Paracelsus und die Chemiater eingestellt, ebenso gegen das Chinin, den Tee und das Antimon. Er schrieb die Lettres choisies, die in mehreren Ausgaben herausgekommen sind. WEPFER besaß wohl die Ausgabe von 1683 in Frankfurt.

31 Johann Drawiz lebte in der Mitte des 17. Jahrhunderts, war Arzt in Leipzig und schrieb Von der Krankheit des schmerzmachenden Scharbocks.

32 Jean Baptist van Helmont (1577-1644) hat ein eigenartiges Gemisch von idealistischspiritualistischer und empirisch-naturwissenschaftlicher Vorstellungen miteinander vermischt. Er bewunderte Paracelsus und bekämpfte ihn zugleich. Er ist das Haupt der chemiatrischen Richtung in der damaligen Medizin, und er ist der Entdecker der Kohlensäure (= gas sylvestre). Vgl. Anm. 45. 
bend gestorben sei, weil er den Aderlaß verachtet habe. Die gleiche Litanei schreit einem auch bei andern entgegen. Die französische Komödie ${ }^{33}$ dagegen spottet verächtlich, es gebe ja nur folgende Behandlung jeglicher Krankheit: vom Blut befreien, purgieren und Klistiere geben usw. Ganz entschieden geißelt der Zauberer François Citoys ${ }^{34}$ die Blutangst (haemophobia) schon im Widmungsbrief an Seine Eminenz den Kardinal Richelieu, dann in einer Art Parodie und schließlich in ausführlicher Darlegung. Mit vollem Munde läßt er in ganz Europa verlauten, die Pariser Schule sei bei der Behandlung akuter Krankheiten unvergleichlich erfahren und erfolgreich.)

Seit jener Zeit bis heute wird von mir selten und von andern unserer Ärzte sehr selten bei anhaltenden Fiebern zur Ader gelasssen, außer wenn eine Brustfellentzündung damit verbunden ist. Diese Fieber waren meist bösartig und mit Petechien verbunden (Flecktyphus). Die Feldscher und Dorfbader wagen den Aderlaß oft, denn am ersten und zweiten Krankheitstage wirkt er sich nicht schlecht aus. Nach dem dritten Tage gibt es entweder einen tödlichen Ausgang oder eine Verlängerung der Krankheit. Manchmal haben sie bei Trockenheit der Zunge die ,Venae raninae ${ }^{6}$ mit Erfolg eingeschnitten. In unserer Nachbarschaft ist ein Dorf, Riedböhringen, in Sichtweite des vornehmen Grafen von Fürstenberg, in welchem, Ende letzten Frühjahrs anfangs Sommer, über sechzig Menschen an einem bösen Fieber darniederlagen. Alle genasen, wobei nicht ein einziger starb, obwohl keiner einen Aderlaß oder Medikamente anwandte. Dies aber wegen der Armut,

33 Jean-Baptiste Poquelin, genannt Molière (1622-1673) schrieb die Komödie Der eingebildete Kranke, die 1673 in Paris zum ersten Male aufgeführt wurde. In Le Malade imaginaire (Nouveaux Classiques Larousse par Yves Hucher, Paris 1964, S. 132, Zeile 77 und 78, 89 und 91) läßt Molière den Bachelierus sagen: «Clysterium donare, postea seignare, ensuita purgare.» WEPFER spielt wohl auf diese Stelle an.

34 Franciscus Citesius (François Citoys 1572-1652) war Leibarzt des Kardinals RicheLIEU und Dekan der Medizinischen Fakultät von Poitiers. Er schrieb Opuscula Medica, Paris 1639. Darin findet sich ein Kapitel mit dem Titel: «De tempestivo phlebotomiae ac purgationis usu. » Die Stelle im Widmungsbrief an den Kardinal Richelieu, auf die Wepfer anspielt, lautet im Original: «Propterea cum succisivis horis E.V. muneris mei nuper rationem redderem, et ex aegro tantibus, quos perambulabam, plaerique morbis acutis conflictarentur, quibus sola fere venaesectione, tamdiu repetita quamdiu vis morbi suaderet et vires ferrent, opem allaturum me sponderem post multa de phlebotomiae et epaphaereseos necessitate in morbis acutis in medium prolata, illa mihi quae ea de re viderentur in usum et commodum publicum scribere, et scripta typis mandare iussit, ut hinc discant haemophobi sanguinis missionem tempore et loco non aversari: Et si forte medicus aliquis ex Erasistrati haemophoborum principis secta non omnino pertinax rationibus nostris aurem commodere non recuset, easdem esse agnoscat quas habent Hippocrates et Galen. cum Lutetiana schola qua in acutorum morborum curatione nulla in tota Europa peritior et felicior est. » 
denn durch verbündetes Militär waren sie jeglicher Mittel beraubt worden. Vollkommen ohne Wein, mußten sie während des ganzen Krankenlagers Wasser, das sie fanden, trinken. Sie kamen allein durch diesen Umstand davon. Während ich dies schreibe, erzählt mir ein nicht unerfahrener Chirurg, im heimatlichen Dorfe Buchberg habe er neulich im November und Dezember bei einigen Bauern von hablichem Stande sofort nach einem Schüttelfrost zur Ader gelassen und bald darauf Schwitzmittel bei den, Weinlosen ${ }^{6}$ angewandt, und die Abstinenten seien in Kürze gesund geworden. Das Dorf sei nicht gerne länger krank, keiner sei gestorben, weil der Wein [fehlte ?]. Die Geschichte des Bauern von Donaueschingen muß noch angefügt werden. Er wurde von einem brennenden Fieber befallen und trank während einiger Monate reichlich süßen Wein. Schließlich wurde er wahnsinnig ... [?]

Früher habe ich öfters bei intermittierenden Fiebern nach dem dritten Tage zum Aderlaß geraten, aber nachdem ich erfahren hatte, daß man ihn manchmal übertrieb, ihn andauernd, auch zwei- und vierfach und schlecht auszuführen pflegte, ordnete ich ihn dann seltener an. Ich merkte, daß es besser und auch schneller sei, das angenehmere Fiebermittel zu nehmen. Ich muß noch dieses beifügen: 1651, zu Beginn des Frühlings, befiel ein fiebriger Schüttelfrost einen unserer Weinbauern, der an einem Drei-Tage-Fieber litt, während er bei klarem Wetter und Südostwind im Weinberg Schößlinge beschnitt. Er glaubte, es sei ein Vorzeichen der Tertiana, rief den Famulus eines unserer Chirurgen herbei und verlangte einen Aderlaß von ihm, den auch dessen Meister bei solchen Anfällen zur Erleichterung wagte. Dem Bettlägerigen öffnete er die Ader, und nachdem noch nicht die übliche Menge Blut herausgeflossen war, fiel der im Bett Sitzende nach hinten und hörte bald darauf zu atmen auf. Vergeblich waren alle Versuche, die sonst bei einer Synkope angewandt werden. Man hatte beobachtet, daß das gleiche schon andern vom Aderlaß im Anfall geschehen war.

Hier steht dem Abschweifen ein weites Feld offen, und ich kann zweifellos vieles, was die Gesundheit der Menschen betrifft, erörtern. In Italien mißbilligen sie den Aderlaß bei Fiebern, besonders bei den bösartigen, wie man dies bei Oktavian Roboretus im Buch Über den Flecktyphus ${ }^{35}$ nachlesen kann. Auch sonst sind die Italiener beim Aderlaß vorsichtiger und mäBiger. Die Deutschen treten in deren Fußstapfen, wie man das am Beispiel

35 Octavianus Roboretus (Ausgang 16. Jahrhundert) war Arzt in Trident. Er schrieb einen tractatus de febre petechiali Tridenti 1591 publice vagante. Nach der Angabe von Rhode (vgl. Anm. 16) hat Sennert (vgl. Anm. 36) ihn fast wörtlich abgeschrieben. 
des Verdienstes Eures Sennerts ${ }^{36}$ sehen kann. Die Helmontianer ${ }^{37}$ verwerfen ihn nun auch nicht mehr gänzlich. Die Franzosen dagegen verschwenden das Blut, empfehlen vor allen andern den Aderlaß nicht nur bei irgendwelchen Krankheiten, sondern besonders bei Fiebern. Nach dem Urteil vieler folgen sie mehr dem Beispiel Botallis ${ }^{38}$ als Galens. Im Buch Medizinische Werke, Paris 1639, berichtet Citoys ${ }^{39}$ schon sofort in der an Seine Eminenz, den Kardinal Richelieu, gerichteten Widmung, daß er versprochen habe, fast nur mit dem Aderlaß zu helfen, als unter dessen Regierung viele Patienten von akuten Krankheiten befallen waren. Dieser Aderlaß werde solange wiederholt, wie die Macht der Krankheit dauere und die Kräfte der Kranken es erlaubten. So pocht er auf die Autorität der Pariser Schule und, seiner Ansicht nach, ist in ganz Europa keine Schule erfahrener und glücklicher in der Heilung der akuten Krankheiten. Hippokrates und Galen hätten die Blutangst des Erasistratos übernommen ${ }^{40}$. Diesem Buch wird, ohne daß ein Autor genannt wäre, eine Parodie über die römischen Ärzte, die Angst vor dem Blut haben, vorausgeschickt. Der Anfang lautet: ,So also setzt sich im römischen Verstand der Irrtum fest und eitle, bedingungslose Furcht ?` und fährt fort: ,Das mächtige Rom, von kühnem Mut, furchtlos vor vergossenem Blut und so oft zu großzügig im Töten des Feindes, ... von der offenen Vene

36 Daniel Sennert (25. November 1572 bis 21. Juli 1637) wurde am 15. September 1602 Professor für Medizin in Berlin. Er war ein Vielschreiber und Kompilator. Man hat ihn sogar des Plagiates beschuldigt. (Vgl. Anm. 35). Nach HäsEr, Geschichte der Medizin, III, 3, S. 422, hat er als erster den Scharlach in Deutschland beschrieben. (Die allererste Beschreibung des Scharlaches stammt aus dem Jahre 1552 durch Grovanni Philippo INGRASSIAS [1510-1580]).

$37 \mathrm{Zu}$ diesen Helmontianern, die die Ferment-Lehre und die damalige chemische Richtung vertraten, gehören u.a. Franciscus Sylvius (1614-1672), Thомas Willis (1622-1675) und Raymond de Vieussens (1641-1716).

38 Leonhard Botel (Botallus) (1530- ?) war Arzt von Asti im Piemont. Um 1575 wurde er Leibarzt HeInRICHs III in Frankreich und führte das öftere und reichliche Blutentziehen bei chronischen Leiden in Frankreich ein.

39 Der lateinische Text ist wörtlich in Anm. 34.

40 Hippokrates von Kos (460-377 a. Chr.) hatte genaue Indikationen für den Aderlaß gestellt. Erasistratos aus Keos (330-250 a.Chr.) behauptete, daß nur in den Venen Blut sei und daß das Pneuma, das durch die Lungen ins Herz gelange, durch die Arterien im Körper verteilt werde. Von seinem Lehrer CHRYsIPP hatte er einen Horror vor dem Aderlasse übernommen, der noch durch eigene unerfreuliche Erfahrungen verstärkt wurde. Er ließ den Aderlaß deshalb fast vollständig weg. Nur in einigen wenigen besonderen Fällen wandte er ihn an. Galen aus Pergamon (130-201) führte dann den Aderlaß für alle möglichen Krankheiten ein, verlangte aber genaue Indikationen (vgl. J. BAUER, Geschichte der Aderlässe, München 1966). 
schreckt es ab, und vom herausgelassenen Blut erbleicht es mit bestürzter Miene.' Etwas später fügt er hinzu : ,Jetzt wütet zügellos die Mattigkeit im ganzen Körper oder das Fieber vom Durste begleitet erschöpft die Glieder, die Seuche brennt das Mark aus, still und heimlich, mit Feuer und Gift dem roten Gerinnsel schadend; Rom wagt nicht dem Leben mit dem Aderlasse zu Hilfe zu kommen.' Er schließt: ,So vertreibe das Entsetzen aus dem Gemüte und wage bei schwerer Krankheit den Aderlaß. Leg die leere Furcht beiseite und erwirb eine bessere Ansicht. Nimm die starke, göttliche und gute Hilfe an, womit Dir eine Panazee erwächst, die wie keine geeigneter gegen den Schmerz und besser zum Schutze des Lebens ist."

Dann folgt in diesem Werklein eine Darlegung des rechtzeitigen Gebrauchs von Venenschnitt und Abführen, im Gegensatz zu den ,Blutängstlichen (haemophobi) ${ }^{6}$. In dieser Auseinandersetzung sucht er seine Meinung mit Überlegungen, Autoritäten und Erfahrungen zu festigen. Er gibt im Kapitel 5, Seite 26, zu, daß die Pariser einen ausgedehnteren und häufigeren Aderlaß ohne Entkräftigung ertragen als die Einwohner der Languedoc, von Narbonne und dem ganzen Gebiet um das Mittelmeer. Dort habe er beobachtet, daß häufig Ohnmachten und krampfartige Synkopen nach Gefäßeröffnung vorkämen ${ }^{41}$. Dem stentorischen Geschrei dieses Mannes füge ich noch Guy Patin, einen weit und breit berühmten Pariser Arzt, bei. So beginnt dieser in den Briefen, im dritten Brief, Seite 10: Auf der ganzen

41 Das Werk von Françors Citoro hat folgenden ausgeschriebenen Titel: Francisci Citesii, regis et eminentissimi Cardinalis Ducis De Richelieu Medici atque Facultatis Pictavensis Decani Opuscula Medica. Parisiis, apud Sebastianum Cramoisy Typographum Regium, viâ Jacobeâ sub Ciconiis, MDCXXXIX.

Aus dem Inhaltsverzeichnis:

Widmungsbrief an Kardinal Richelieu

Inhaltsverzeichnis

Ad Romanos Medicos «haimophobus» Parodia

De tempestivo Phlebotomiae ac purgationis usu, dissertatio adversus haemophobos, S. $1-52$.

usw.

In dieser Dissertation über den rechtzeitigen Gebrauch von Aderlaß und Purgation sagt Citoys im 5. Kapitel, S. 26: «Hinc est quod Lutetiae, cuius latitudo est 48. gr. 50. m. et tota ea Galliae parte quam Sequana et Ligeria dicitur, ubi tranquille et lente plerumque vivitur, ac proinde sanguis uberior colligitur; largior et frequentior phlebotomia sine virium exolutione celebratur, quam Tolosae, Narbonae et toto eo tractu quem mare Mediterraneum lambit, ubi parce et tenuiter vivitur. Unde fit ut tot frequentes leipothymiae apud ipsos, imo interdum syncopes convulsivae vase aperto contingant, quales saepe in iis regionibus observavimus, praesertim in viris biliosis.» 
Welt mache kein Heilmittel solche und so viele Wunderdinge wie der Ader$\mathrm{la}^{42}$. Er unterstreicht, sehr viele Wunder ${ }^{6}$. Herr Cousinot, von einem heftigen und wilden Rheumatismus befallen, habe den Aderlaß in acht Monaten 64 mal erlaubt, wozu ihn der Vater und der Schwager als Ärzte von Paris überredeten. Nach so vielen Aderlässen begannen sie ihn abzuführen, wovon die Schmerzen besserten und er geheilt wurde ${ }^{43}$. Vor diesem Wunder schrekken Drawiz ${ }^{31}$, Möllenbrock ${ }^{44}$ und andere auch nicht zurück. Auf diese Art behandeln sie Kranke, die an einer fliegenden Gliedersucht leiden, die sich aber schon gegen einen Rheumatismus hin entwickelt.

Gegen das Ende dieses Briefes nennt Patin den Helmont einen ,mechant pendart Flamand' (boshaften, flämischen Galgenstrick), der als Irrer gestorben sei, weil er den Aderlaß vernachlässigt habe ${ }^{45}$. Dort kommt auch ein 7 jähriger Brustfellkranker mit dreizehn Aderlässen in fünfzehn Tagen wahrlich wunderbar davon ${ }^{46}$. Brief 21, Seite 82 : Einem Greis, der an Peripneumonie litt, ließ man achtmal zur Ader und jedesmal neun Unzen. Später wurde er viermal purgiert, und wunderbarerweise ging es ihm viel besser, und er selbst glaubte an ein Wunder. Wirklich geheilt, volbrachte er an sei-

42 Guy Patin, Lettres choisies de l'an 1645 jusqu'en 1672, La Haye (Frankfurt) 1683. Brief 3, S. 10: «Il n'y a point de remédes au monde qui fassent tant de miracles que la saignée» (7. April 1645).

43 Guy Patin, Lettres choisies, Brief 3, S. 10: «NB. Environ l'an $1633 \mathrm{Mr}$. Cousinot qui est aujourd'hui premier Medecin du Roy fut attaqué d'un rude et violent rhûmatisme, pour lequel il fut saigné 64. fois en 8. mois, par ordonnance de Mr. son Père et Mr. Bouvard son Beaupère. Aprés avoir été tant de fois saigné on commença à le purger, dont il fut fort soulagé et en guérit à la fin» (4. Juli 1645).

44 Valentin Andreas Moellenbrock (gestorben 8. August 1675) war Arzt und Medizinprofessor in Erfurt und Stadtphysikus in Halle. Vielleicht spielt Wepfer auf den Tractatus de Varis seu Arthritide vaga scorbutica 1672 an.

45 Guy Patin, Lettres choisies, Brief 3, S. 12: «Pour Van Helmont il n'en fera plus. C'étoit un méchant pendart Flamand, qui est mort enragé depuis quelques mois. J'ay vû tout ce qu'il a fait. Cét homme ne méditoit qu'une Medecine tout de secrets Chymiques et Empiriques et pour la renverser plus vîte, il s'inscrivoit fort contre la sagnée, faute laquelle pourtant il est mort phrenetique» (7. April 1645).

46 Guy Patin, Lettres choisies, Brief 3, S. 11: «J'ay autrefois traité en cette ville un jeune Gentilhomme âgé de sept ans qui tomba dans une grande pleuresie pour s'être trop échaufé à jouer à la paume, ayant même recue dans la jeu un coup de pied au côté droit, qui provoqua la fluxion plus grande. Son Tuteur haissoit fort la saignée et je ne pûs opposer à cette haine qu'en bon conseil, qui fut d'appeller encore deux nos anciens, Messieurs Seguin et Cousinot. Il fut saigné treize fois et fut guéri dans quinze jours comme par miracle, le Tuteur même en fut converti» (7. April 1645). 
nem Arzt kein Wunder, indem er ihm nur eine Statue schenkte ${ }^{47}$. Brief 52, Seite 175: Die holländischen Ärzte bekrittelt Patin, sie seien eher Schinder als Ärzte, weil sie bei bösen Fiebern vor allem schweißtreibende Mittel und kaum je den Aderlaß anwenden würden ${ }^{48}$. Mehreres lasse ich aus. Wie dem auch sei, der Gegner der Deutschen und Italiener, dieser Pariser unseres Jahrhunderts, ist ganz unterhaltend zu lesen. Dabei bleibt aber wahr, daß, während die Pariser die Römer und Deutschen verhöhnen, die Verständigen dennoch herausfinden, was falsch und was ohne Überlegung an dieser Ansicht ist, wenn sie die Schriften der Römer und der übrigen Italiener wie auch der Deutschen durchblättern. Mit den meisten nenne ich das Buch über den Mißbrauch des Aderlasses von Pietro Castelli ${ }^{49}$, der zusammen mit den römischen Ärzten beobachtet hatte, daß durch den Aderlaß die Rekonvaleszenz, in Übereinstimmung mit Galen, vergleiche Methodus Medendi 10, verlängert wird. Von andern Schäden, die dort beschrieben sind, zu schweigen. Einen auserlesenen Entwurf gab unser ... [?] verehrter, alter Lehrer in Straßburg, Melchior Sebiz, heraus: ,Galen, über die Heilung mit dem Aderlaß $3^{60}$ Daraus geht hervor, daß jener ihn gestattet, aber den planlosen, unüberlegten und für die Kranken schädlichen zurückweist. Herr Georg Bal-

47 Guy Patin, Lettres choisies, Brief 21, S. 82: «Mon beau Père a pensé mourir ce dernier mois de Janvier, mais il a obtenu quelque terme de la Parque. En cette dernière attaque il a été saigné huit fois des bras, et chaque fois je luy en ai fait tirer neuf onces quoi qu'il ait 80. ans. C'est un homme gras et replet. Il avoit une inflammation de Poûmon avec delire, et outre cela il a la pierre dans les reins et dans la vessie. Après les saignées je l'ay purgé quatre bonnes fois avec du sené et du sirop de roses pâles: il semble qu'il est rajeuni. Bien de gens auroient peine à croire cela et croiroient plûtôt quelque fable d'un Julep cordial. Il m'en témoigne bien du contentement, mais quoi qu'il soit fort riche, il ne donne rien non plus qu'une statue.»

48 Guy Patin, Lettres choisies, Brief 52, S. 175: «On dit qu'en Holande le nombre des malades est effroyable. Ils meurent tous nonobstant de fréquent usages des sudorifiques. Où est-ce que ces gens-là ont appris la Medicine? Saigner trés-peu, ou point du tout: purger peu et avec des poudres, des pilules ou de l'antimoine, et puis faire suer des malades, qui ont les vaisseai, le ventre et l'habitude du corps plein d'ordures et de beaucoup d'impuretés. N'est-ce pas-là ètres des Bourreaux plutôt que des Medecins? » (26. August 1654).

49 Petrus Castellus (gestorben 1662) war Professor Primarius für Medizin in Messina.

50 H, Fischer, Johann Jakob Wepfer, 1620-1695. Ein Beitrag zur Medizingeschichte des 17. Jahrhunderts, Zürich 1931, S. 3, nennt Johann Albert Sebiz (1614-1685) den Anatomielehrer J. J. Wepfens in Straßburg. Hier jedoch bezeichnet J. J. Wepfer selbst Melchior Sebiz II (19. Juli 1578 bis 25. Januar 1671) als seinen Lehrer in der Straßburger Studentenzeit (1638-1643). Melchior Sebiz II ist der Vater von Johann Albert SeBIZ und wurde 1612 Professor für Medizin in Straßburg, 1625 Stadtphysikus und schrieb 
thasar Mezgers Thesen über den Aderla ${ }^{51}$ verdienen gelesen zu werden. Damit soll, nach Ansicht von Laville [?], ausgezeichnet pariert werden. Man erwäge, was Johann Alfons Borelli über die Bewegung der Tiere ${ }^{52}$ am Ende des zweiten Buches, Vorschlag 233, sagt: ,Den großen Aderlaß sollen einige über alles rühmen, andere ihn als gefährlich bemängeln, und er schließt daraus, daß jener wenig nütze und wenig schade. Wenn er aber so erfolgreich und lobenswert wäre, würden die Kranken in Frankreich und Spanien, wo allen Fiebernden zur Ader gelassen wird, in vermehrtem Maße gesund sein, mehr als in Italien und an den andern Orten, wo nie zur Ader gelassen wird. Im Gegensatz dazu müßte der Anteil der Kranken in Frankreich und Spanien größer sein. Beides ist aber nicht wahr. Nicht nur bei Fieber, sondern auch bei andern Krankheiten mit und ohne Fieber werden von den Praktikern so viele Aderlässe empfohlen und nicht selten auch ausgeführt.

Bei Kopfkrankheiten würde ich der Reihe nach folgendes tun: Bei Kopfschmerzen, wenn die Kranken vollblütig und kräftig sind, auch bei Schädelprellungen, habe ich den Aderlaß mit Erfolg angewandt; bei sehr heftigen und anhaltenden Hemikranien, bei denen die sonst wirksamen Abführmittel und blasenziehenden Pflaster vergeblich waren, empfahl ich bei zwei Frauen und einem vornehmen Herrn mit Erfolg den Arterienschnitt an der Schläfe, nachdem ich sie zuvor aufgeklärt hatte. Er ist nämlich nicht so gefährlich, wie man meint. Man glaubt, daß man den Schwindel auf Grund von Vollblütigkeit bei Kranken beiderlei Geschlechts nur durch den Aderlaß beheben könne, und nicht selten ist er erfolgreich. Ich habe bemerkt, daß beim Hirnschlag der Aderlaß nicht so erfolgreich ist, wie einige sagen; aber viele empfehlen ihn. Beim serösen (Hirnschlag) verschlimmert sich das Übel und der häufigere Insult wird beschleunigt, wie ich neulich bei einem 45 jährigen Manne beobachtet habe, bei dem die Epilepsie und Hemiplegie abwech-

den von Wepfer angeführten Commentarius in libri Galeni de curanda ratione per sanguinis emissione, Straßburg 1652. Johann Albert Sebiz (21. Oktober 1614 bis 8. Februar 1685) promovierte 1640 in Straßburg, war anschließend in Basel, Montpellier und Paris. Er erhielt die Professur für Anatomie und Botanik in Straßburg erst 1652.

51 Georg Balthasar Metzger (1623-1687) war anfänglich in Giessen, dann in Tübingen Professor für Medizin. 1652 durde er Mitglied der Academia naturae curiosorum und später zweiter Adjunkt des ersten Präsidenten, J. L. BAUsch. Er war der Schwiegersohn von Rosinus Lentilius, der von WePFer im Buch über die Kopfkrankheiten häufig zitiert wird.

52 Johannes Alfonsus Borelli (28. Januar 1608 bis 31. Dezember 1679) war Philosoph und Professor der Mathematik in Pisa. Seine Biographie befindet sich in De motu animalium, Ausgabe 1681. 
selten. Beim blutigen (Hirnschlag) oder bei der Hirnblutung ist er unnütz. Das Blut wird nicht mehr ins Gefäß resorbiert, und vom Blutabzapfen werden die Kräfte geschwächt, worauf der vorzeitige Tod, zur Schande der Ärzte, dem Aderlaß in die Schuhe geschoben wird. Die Empiriker bei uns versuchen die Epilepsie mit dem Aderlaß zu beheben, den sie an verschiedenen Körperstellen sehr häufig, oft auch sehr reichlich, wagen. Diesem stimmt auch Patin in Brief $123 \mathrm{zu}^{53}$. Nicht immer habe ich den Aderlaß abgelehnt: Neulich habe ich einer sehr kräftigen Frau von gesundem Aussehen, der um das 41. Lebensjahr die Menses ausblieben und die seit anderthalb Jahren einige epileptische Anfälle hatte, meistens um den Neumond herum, ihn in den einzelnen Monaten ungefähr dreimal, bald an einem Fuße, bald an der Hand oder an einem Arme empfohlen. Darauf wurde sie weder von einem Anfall noch von einem leichten Ziehen in der Wange oder in der Lippe befallen. Das pflegte sonst ein Vorzeichen des Übels zu sein. Sie wird damit fortfahren, aber jedesmal nur mit einem spärlichen Aderlaß, zusammen mit antiepileptischem Pulver.

Zahnschmerzen werden manchmal durch einen Aderlaß in Schranken gehalten. Als junger Mann litt ich selbst daran, und daher machte ich den Aderlaß zwischen dem 17. und 24. Lebensjahr, bald einmal, bald zweimal im Jahr. Als ich aber in Padua zweimal, auch wenn nur wenig Blut herausfloß, in Ohnmacht fiel, unterließ ich ihn dann ohne Schaden bis heute. Bei Atemnot und Asthma, durch Empyem, Brustwassersucht und Bronchienverstopfung bedingt, und auch beim krampfartigen Asthmaanfall riet ich nie zum Aderlasse, da bei diesen Krankheiten wegen der sehr großen Enge die Notwendigkeit anderes anrät, damit jeder rasch davon befreit werde. Schneller und besser als ein Aderlaß nützen krampflösende und schweißtreibende Mittel. Das bezeugt schon die Erfahrung. Kommt eine Ohnmacht dazu, laufen sie keine Gefahr. Ich scheue mich bei den Blutspuckenden den nötigen Aderlaß zu machen, wie auch bei vielen Phthisikern. Beim Herzklopfen ist der Aderlaß von Nutzen, sofern die Patienten nicht abgemagert sind. Beim Keuchhusten habe ich den Aderlaß nie gewagt. Das Bluterbrechen habe ich eher mit Ruhe und blutstillenden Mitteln beherrscht. Ich glaube, daß der Aderlaß bei diesem gefährlich ist, da meistens sehr viel Blut in die Magenhöhle ausfließt.

${ }^{53}$ Guy Patin, Lettres choisies, Brief 123, S. 364: «Je croi qu'il n’y a aucuns remédes AntiEpileptiques, Messieurs Seguin, Riolan, la Vigne et Moreau étoient de cét avis. Ceuxque Crollius et la nation des Chymist content pour tels sont des fictions et des pures fables» (14. Oktober 1664). 
[Auslassung wegen Wiederholung] Der französische Flüchtling und andere, die herumstanden, baten um einen Aderlaß. Dennoch wies ich dies zurück, da schon mehr als genug Blut verloren sei und wir viel eher den Blutersatz überdenken müßten. [Auslassung wegen Wiederholung.]

Beim ,Affectus hypochondriacus ${ }^{6}$ lehnte ich ihn manchmal nicht ab. Bei Dysenterie riet ich nie zum Aderlaß, auch nicht beim ,fluxus hepaticus ${ }^{6}$, der so genannt wird, wenn er vom serös-wässrigen Blut kommt. Bei der galligen Kolik habe ich ihn nie angeraten, obwohl ihn Citoys in seinem Medizinischen Werk empfiehlt ${ }^{54}$, weil ich beobachtet habe, daß vom Blutverlust und von den Abführmitteln die Lähmung beschleunigt wird. Man gebe sich mehr Mühe den konvulsiven Krampf der Eingeweide so rasch als möglich und erfolgreich zu lösen.

Beim täglichen Blutharnen, verursacht durch einen rauhen, in den Nieren hängengebliebenen Stein, erlaube ich den Aderlaß manchmal, um eine Nierenentzündung zu verhüten. Aber mit mehr Erfolg habe ich ihn weggelassen und die Harnwege nur mit Laxantien, unter Weglassung der wärmenden Diuretika, behandelt. Keinem Wassersüchtigen habe ich jemals zum Aderlaß geraten. Bei vollblütigen Schwangeren ist der Aderlaß oft nötig. Bei einigen habe ich sogar dreimal während der Schwangerschaft dazu geraten. Wenn sich eine größere Uterusblutung ereignet und ein meistens unvermeidlicher Abort droht oder schon im Gange ist, ließ ich ihn weg. Er ist nämlich todbringend, wie ich bei einigen erfahren habe. Vielen nützen Ruhe und Mittel, die die Unruhe des Blutes besänftigen, mehr. Bei einer vornehmen Frau begannen neulich, Ende Oktober, im Beginn des achten Schwangerschaftsmonates, die Menses, wie sie es nannte, zu fließen. Für kurze Zeit hörte der Fluß auf, kam aber wieder Ende November, aber wenig während zwei Tagen. Bis dahin gebrauchte sie keine Mittel. Sie bemerkte keinerlei Vorzeichen. Am 10. Dezember kam diese Blutung wieder, dauerte die ganze Nacht, mit starken Kreuzschmerzen, Bauchkrämpfen und Wehen, mit denen sie ziemlich große Gerinnsel ausschied. Sofort empfahl ich vollständige Ruhe. Zusammen mit Fleisch solle sie Hauseblasen ${ }^{22}$ kochen und von dieser ungesalznen Brühe eine Süßmandelemulsion und gewöhnliche Suppen zubereiten. Von der folgenden Mixtur solle sie löffelweise nehmen: Nimm 5 Unzen Wasser von Wegerich, 4 Skrupel zubereitete Korallen, je 1/2 Drachme Drachenblut und Japanische Erde, 1/2 Unze

${ }^{54}$ Francisci Citesii opuscula medica, Paris 1639, Dissertatio de tempestivo usu Phlebotomiae ac Purgationis, Caput IX, S. 38-40. 
Berberitzensirup, Mische ${ }^{55}$. Davon verringerte sich die Blutung. Durch die Bettruhe wurde die Blutung allmählich ganz aufgehoben, die Wehen und die Kreuzschmerzen verschwanden. Am 30. Dezember gebar sie leicht einen schönen und gesunden Sohn, und es geht ihr bis heute gut ... [?] Vor einigen Jahren - am 8. Oktober 1667 - war bei meiner geliebten Frau der gleiche Geburtsausgang. Beim Menstruationsausfall gestatte ich mit gutem Gewissen bei Mädchen den Aderlaß der Vena saphena. Ich lehne diesen sonst bei Schwangeren und bei solchen vor dem Geburtstermin ab, obwohl sie überzeugt sind, dieser Aderlaß verhelfe ihnen zu einer glücklichen Geburt und verringere die Schmerzen nachher. Ich kannte einige, die an Blasensteinen litten und den Aderlaß fleißig betrieben, aber mit wenig Erfolg. Solchen, die an Schmerzen der Hämorrhoiden litten, gestand ich den Aderlaß zu, aber viel eher deren Eröffnung, die durch Feigenblätter oder Blutegel gemacht wird. Bei Rasenden, Tobenden und ähnlichen Krankheiten wird der Aderlaß nicht selten als nutzbringend angeraten. Ich habe beobachtet, da $\beta$ einige wütender wurden, wenn nicht die erforderliche Menge herausgelassen und sie wiederholt mit Brechmittel ermüdet wurden.

Einem Bauern, der von einem tollwütigen Wolf gebissen wurde und einige Monate danach die Hydrophobie bekam, wurde zuerst ein Brechmittel aus Antimon gegeben und dann am Arm eine Vene geschnitten. Sobald das Blut zu fließen begann, fiel er rückwärts vom Stuhl und starb. Ich schrieb einige Krankengeschichten über solche, die, in verschiedenen Gegenden, von Wölfen gebissen worden waren. Diese werde ich, so Gott und meine Kräfte es erlauben, an das Collegium Curiosorum übermitteln ${ }^{56}$. Bei Podagra und fliegender Gliedersucht habe ich während der Schmerzen nie einen Aderlaß angewandt, da er eher quält als hilft. Sonst nützen öfters, ungewollt zwar, Aderlässe zur Vorbeugung von Schmerzen. Ich kannte einige, die jeden Monat Skarifikationen ins Fleisch unter dem Daumengelenk beidseits anlegten,

\begin{tabular}{|c|c|c|}
\hline 55 Rp. & Nimm & \\
\hline Aq. centumnod. $\zeta \mathrm{v}$ & Wegerich-Wasser & 5 Unzen \\
\hline $\begin{array}{l}\text { corall. pp. } \quad \ni \text { iij } \\
\text { Sang. drac. }\end{array}$ & $\begin{array}{l}\text { zubereitete Korallen } \\
\text { Drachenblut }\end{array}$ & 4. Skrupel \\
\hline T. Jappon. āā $3 \mathrm{~s}$ & Japanische Erde je & $1 / 2$ Drachme \\
\hline Syr. berber. $\tilde{\xi} \mathrm{s}$ & Berberitzensirup & $1 / 2$ Unze \\
\hline Ms. & Mische & \\
\hline
\end{tabular}


einige sogar auch im ersten Gelenk mit Erfolg ... [?] ohne Anlegen von Schröpfköpfen. Bei schweren Schädel- und Brustprellungen, sei es durch einen Sturz oder einen Schlag, pflege ich den Aderlaß eher frühzeitig zu machen, selten jedoch bei Wunden, Frakturen und Ausrenkungen, außer es sei eine Entzündung zu befürchten. Bei Krätze, Räude (impetigo) und anderen Hautkrankheiten lehne ich den Aderlaß nicht ab. Bei einem Gelbsüchtigen wandte man ihn aus einem besonderen Grund an. Vor einigen Jahren riet man ihn einem meiner Freunde in Frankreich an, zu wiederholten Malen. Davon wurde er ganz matt. Nach üblichem Brauch gab man ihm dann Abführmittel, wodurch die Mattigkeit verschwand. Was nützt er bei Syphilis, was bei Skorbut ... [?]

zu 4

Daraus wurde mir die Bewegung und Vortrefflichkeit des Blutes bekannt. Sooft mir eine Menge desselben gegeben wurde, aus Arm, Fuß oder Schenkel herausgelassen, immer nahm ich mir die Muße es sorgfältig zu betrachten. Ich sorgte dafür, daß es an einen kühlen Ort gestellt wurde, und nach ein bis zwei Stunden habe ich das Blut mit einer Feder oder einem Rütlein mit Umrühren von der Gefäßwand getrennt, damit sich das Serum besser vom Geronnenen abscheide und ich dann beides nacheinander untersuchen konnte. Die Oberfläche des Gerinnsels war bei Jugendlichen und zügellos Lebenden, z. B. körperlichen Ausschweifungen, ganz rot und leicht zerreißlich. Bei andern war sie bald gesprenkelt, bald wie mit einer Haut bedeckt, dunkel, bläulich oder grünlich. Während ich schnitt, ging die Haut weg, und der Rest trübte sich mit zerfallenden, schwimmenden Bröckel. Diese Haut des Blutes habe ich öfters ganz abgezogen, wobei aber das Blut in kleinen Gefäßen aufgefangen worden war. Manchmal war sie so dick wie ein mittlerer Messerrücken, sehr zäh, so daß ich sie mit den Fingern am Rande fassen konnte, ohne daß sie zerriß. Aus unsichtbaren Poren wurden dunkelgelbe, klare, salzige Tröpfchen ausgeschwitzt, in Farbe und Geschmack dem Serum, worin das Gerinnsel erschien, ähnlich. Die gesprenkelte Oberfläche konnte ich mit einem Rütlein abziehen, aber sie zerriß leicht und haftete fest auf dem Gerinnsel. Wenn ich nach der Methode des Willis ein Gerinnsel untersuchte, wobei das Abgesetzte in einem andern Gefä $\beta$ hervorragt, wird die vorher schwarze Oberfläche, einige Stunden der Luft ausgesetzt, ganz rot. Die Haut fand ich dick und zäh bei älteren Leuten, die gesund sind, herumgehen und ihre Verpflichtungen ordentlich erfüllen. Ebenso ist dies bei uns im Kloster Ittingen in unserer Nachbarschaft und im Katharinental 
fast immer der Fall. Bei einem vornehmen Grafen, der selten Fisch und seit Jahren kein Fleisch aß, zeigte sich dies im Blut. Die Oberfläche des Blutes, ob aus Arm oder Bein herausgelassen, war glänzend rot. Bei Kachektischen konnte nicht immer eine dicke Haut abgezogen werden, auch nicht beim Drei-Tage-Fieber nach dem dritten Anfall. Bei Brustfellkranken war beim ersten Aderlaß die Oberfläche ganz rot, beim zweiten schon gesprenkelt oder von einer dichten Haut bedeckt. Aus dieser Haut weissagte ein gewisser Scherer eine ungeheure Fäulnis des Blutes. Auch bei solchen, die gesund sind, sagen die Scherer oft fälschlich aus dieser Haut voraus, daß schwere Krankheit der Leber, der Milz oder des Uterus bevorstünden. Einmal gerann das Blut, das man einem sehr heftig und andauernd fiebernden Greis am Arm entnahm, gar nicht. Ich verzweifelte fast an seiner Genesung. Er genas dann doch endlich, Gott sei es gedankt, und lebte noch einige Jahre.

Das Serum fand ich nach Farbe, Beschaffenheit, Geschmack und Geruch verschieden. Meist war es dunkelgelb, manchmal klar, manchmal trüber, salzig im Geschmack ... [?] Wenn eine Suppe kurz vor dem Aderlaß eingenommen worden war, habe ich das Serum schon einige Male weißer, trüber und fast süß gefunden, was ich der raschen Beimischung des Chylus zum Blutserum zuschrieb ${ }^{57}$. Dadurch wurde meine Ansicht bestätigt, daß der Chylus ohne Zweifel den Magen- und Eingeweidevenen aus Magen und Därmen beigemengt werden kann. Dennoch legt das Blut seine Purpurfarbe im Menschen und in den Vierfüßern, wie auch bei den Vögeln, nicht ab. Bei allen ist die Blutfarbe im Gekröse ähnlich wie in anderen Körperteilen ${ }^{58}$. Notwendigerweise wird der Chylus dort dem Blute beigemengt, da ich bis

57 Eine Parallelstelle finden wir in einem Schriftstück WEPFErs, das den Titel «das menschliche Blut » trägt ( L U P, B P L 249, fasc. 3, fol. 35 R): «Am 7. April 1688 ließ sich meine Frau, ohne vorher Abführmittel genommen zu haben, am rechten Arm eine Vene mit der Lanzette öffnen. Da die Wunde klein war, floß nur wenig Blut heraus, teils fadendünn, teils tropfenweise, Das abgekühlte und geronnene Blut hatte ein gelbes, leuchtendes und salziges Serum. Die Oberfläche war gleichmäßig rot. Nach dem Mittag, nicht lange nach dem Essen, ließ sich meine Frau am linken Arm eine Vene öffnen. Nachdem das Blut geronnen war, zeigte sich eine große Menge Serum, das weiß, trübe und fast scharfem Geschmack (sapore subacido) war. Die Oberfläche war leuchtend rot und ließ sich leicht einreißen. Meine Frau hatte Wein mit Wasser gemischt getrunken... Deshalb wird der Chylus sehr schnell mit dem Blut vermischt. Davon wird auch die Flüssigkeit trübe. Die Weinsäure vermag nicht eine so starke Trübung zu bewirken, wie man glaubt.»

58 Vgl. N. MANI, Darmresorption und Blutbildung im Lichte der experimentellen Physiologie des 17. Jahrhunderts, Gesnerus 18, (1961) 89, wo W. HARvey, De motu cordis, cp. 16, 1628, S. 61-62, zitiert wird: «Das Blut der Gekrösevenen ist von gleicher Farbe und Beschaffenheit wie alles übrige venöse Blut ...» 
jezt - nicht sehr augenfällig - eigentümliche und chylusführende Gänge beobachtet habe, im Gegensatz zu Jakob Heinrich Paulli, der im Brief dies zurückzuweisen versucht, indem er nicht glaubt, daß der ganze Chylus, der aus den Milchvenen und dem ,Ductus chyliferus ${ }^{6}[=$ thoracicus $]$ an die Blutmenge abgegeben wird, in den Mesenterialvenen seine Farbe verliert usw. Bei Gelbsüchtigen, die wie in Safransaft getaucht aussehen, sah ich das Serum manchmal gelb, von bitterem Geschmack. Bei einigen Trinkern roch ich im Blut sogar eine gewisse Schärfe, und bei Betrunkenen schmeckte das Serum fast sauer. Das ganze Serum wurde in ein Zinngefäß getan und auf glühende Kohlen gestellt. Durch die Hitze wurde es zu Gallerte und roch wie Bratenfleisch, woraus ich schloß, daß es zum größten Teil ein ernährender Saft sei. Darin bestärkte mich auch die aus Fleisch zubereitete Gallerte. [Ein Stück Fleisch wird stufenweise eingeschnitten, in eine Kupferpfanne getan und mit Kohlen bedeckt in ganz laues Wasser gestellt. Nach fünf Kochstunden ist es zu Gallerte eingekocht.] Das Serum, die Blut- und Gallegerinnsel zur Trockenheit eingedickt und löffelweise oder gesamthaft einer brennenden Kerze genähert, fangen Feuer und behalten den scharfen Geschmack der gewöhnlichen Galle, sooft ich dies versuchte. Es blieb ein fixes Salz. Aus einer angestochenen Vene sah ich nie Chylus, Serum oder Wasser herausfließen. Nie beobachtete ich, daß mit dem Blute Eiter, Urin, Steinchen, Würmer oder ähnlich Absurdes herausfloß. Bei Leprösen geschah es manchmal, daß nach dem Anstich der Vene das Blut über dem Tuch ganz schwarz wurde. Noch warm wurde es durchgeseiht, aber es blieb nichts von Steinchen oder Würmern zurück, noch konnte ich mit anderen zusammen etwas Derartiges am Frischblut sehen. [Auslassung wegen Unleserlichkeit.]»

Aus diesem Brief erfahren wir eine ganze Fülle von Dingen, die bis dahin von Wepfer noch nie so klar gesagt worden waren.

Da sind zunächst die biographischen Daten. Wir erfahren, daß Wepfer in Straßburg bei Melchior Sebiz II studierte, in Padua sogar bei Johann Rhode zwei Jahre in dessen Hause lebte und in Rom mit Pietro Servi auf die übrigens beispielhaft organisierte Spitalvisite ging. Daneben erzählt uns Wepfer, warum er Krankengeschichten schrieb - dies erklärt die Fülle seines handschriftlichen Nachlasses in Leiden und Zürich - und welches seine Lehrer und Vorbilder dazu waren. Ferner wissen wir um seinen Vorsatz zur Praxiseröffnung und den damit verbundenen Rat Marchettis. Aber nicht nur über den Praxisanfang, auch über die Ausweitung sind Daten da: Arzt der Klöster von Rheinau (seit 1650), von St. Blasien im Schwarzwald (seit 1664), von Katharinental und Ittingen. Daneben ist Wepfer auch besoldeter 
Arzt von Adeligen und am Hofe. Bemerkenswert ist auch, daß sein Sohn Johann Conrad in der Praxis mithilft.

Der Kern dieses Briefes ist aber Wepfers Rückschau auf seine Erfahrung mit dem Aderlaß in der Praxis. Wohl ist Wepfer noch in der medizinischen Überlieferung befangen, er versucht aber, sich bewußt daraus zu lösen und seine persönliche Erfahrung als Richtschnur zu nehmen. Schon sein Eingehen auf die verschiedenen Lehrmeinungen zeigt dies: Die Pariser Schule mit Citoys und Patin steht in schroffem Gegensatz zu den Italienern mit Borelli, den Deutschen mit Sennert und Mezger und den Holländern mit van Helmont. Wepfer ist kritisch, er folgt keiner der drei Richtungen unbedingt, sympathisiert jedoch deutlich mit der ihm nahestehenden italienisch-deutschen Lehrmeinung. Die Darstellung der verschiednen Ansichten über den Aderlaß zeigt uns, wie wenig zimperlich man damals in Gelehrtenkreisen mit seinen Gegnern umgesprungen ist. Sie zeigt uns aber auch, daß Molı̀̀res Spott über die Ärzte von Paris bis nach Schaffhausen gedrungen war. Aber alles dies ist nur der Hintergrund, vor den Wepfer seine persönliche Erfahrung hinstellt. Er schreit seine Erfolge nicht in alle Welt wie ein Guy Patin, er legt sie sachlich-kühl dar. Die rechtzeitige Anwendung des Aderlasses beim Lungenödem des Bürgermeisters von Ewattingen ist für damalige Zeiten ein großer Erfolg. Ebenso erfolgreich ist Wepfer mit dem Aderlaß bei der Hypertonie (Vollblütigkeit). Etwas völlig Neues ist jedoch das Nichtanwenden des Aderlasses, so bei der Enkephalorrhagie und Enkephalomalazie, wie auch bei Blutungen, besonders des Magens, beim Abort und in der Geburtshilfe. Hier haben die Erfahrung und der Erfolg Wepfer den Weg gewiesen. Daß man Patienten mit Frakturen und offenen Wunden nicht zur Ader läßt, ist für Wepfer fast selbstverständlich. Wepfer geht dabei immer von Harveys geschlossenem Blutkreislauf aus, der eine beschränkte Blutmenge annimmt, und daher müsse man auch bei Blutverlust eher den Ersatz des Blutes überdenken als den Aderlaß wagen.

In der Beantwortung der letzten Frage Franks legt uns dann Wepfer noch seine Überzeugung für die Beimischung des Verdauungsaftes zum Blute dar. Diese Vermischung geschehe ohne Farbänderung des Blutes, da ja erfahrungsgemäß das venöse Blut im ganzen Körper gleich aussehe. Wepfer war nicht nur praktischer Arzt, er studierte auch die menschliche Physiologie, besonders diejenige der Verdauuung.

In diesem Briefentwurf Wepfers an Georg Frank von Frankenau erleben wir den großen Schweizer Arzt des Barocks wieder einmal als sorgfältigen und kritisch-kühlen Beobachter, der in seiner Zeit Großes geleistet hat. 